\title{
Pengembangan Perangkat Lunak Payment Remainder di Universitas Bina Darma
}

\author{
Nodi Setiawan'1, Merry Agustina²
}

\begin{abstract}
1 Informatics Departement, Universitas Bina Darma, Palembang, Indonesia 2Vocational Departement, Universitas Bina Darma, Palembang, Indonesia Email: 141420165@student.binadarma.ac.id1', merry_agst@binadarma.ac.id²
\end{abstract}

Abstract

The development of technology has a very important role in all types of human activities such as work, play, and search for information that is currently up to date, like Telegram is a software that uses computer assistance and utilizes cellular technology that is integrated to distribute messages that are integrated through information systems through the media. Bina Darma University has a payment system of tuition in installments, but there are some students who forget to pay off the remaining payments. therefore, an application is needed that can remind students of their payments. To be able to run this software, a Telegram API is needed that has been synchronized with the Telegram Bot service, therefore a software that can send broadcase messages to all students of Bina Darma University through the Telegram application.

Keywords: Technology Development, Instant Message, Telegram Bots

\section{PENDAHULUAN}

Sejalan dengan perkembangan jaman, pencapaian masusia dibidang teknologi kian maju seperti hal-nya aplikasi Telegram yang sedang naik daun. Telegram sendiri adalah sebuah aplikasi yang memungkinkan penggunan atau User untuk mengirimkan pesan Chatting rahasia atau Secret Chat yang di enkripsi end-toend sebagai keamanan tambahan. Dengan menggunakan Telegram anda juga bisa mengirim bukan hanya sekedar gambar dan video, tapi anda juga bisa mengirim dokumen seperti word, excell, PDF dan lainnya tanpa menetapkan besarnya size file yang di kirimkan, juga bisa mengirimkan lokasi anda dengan mudah. Telegram juga merupakan aplikasi yang ringan, cepat, tidak ada iklan, dan Gratis selamanya. Dengan telegram anda bisa membuat Grup yang isinya HINGGA 5000 orang.

Universitas Bina Darma merupakan salah satu institusi pendidikan formal yang mendidik mahasiswa melalui pendidikan sesuai Program Studi yang telah dipilih oleh mahasiswa baik pengetahuan secara umum maupun dengan 
keterampilan khusus yang diberikan oleh dosen pengajar. Universitas Bina Darma seperti kampus pada umum nya yang menyelengarakan pembayaran perkuliahan per-semester kepada mahasiswa yang tengah menempuh pendidikan.

Untuk proses pembayaran biaya kuliah di Universitas Bina Darma menggunakan 2 metode pembayaran. Yaitu dengan cara membayar secara lunas atau dengan angsuran sebanyak maksimal 2 kali angsuran pembayaran. Oleh karena itu pihak Bina Darma memberikan keringanan kepada mahasiswa dalam pembayaran, namun sebagian mahasiswa lupa akan melunaskan pembayaran yang tersisa. Sehingga waktu pembayaran memasuki batas jatuh tempo pembayaran, yang mengakibatkan elearning mahasiswa terblokir dan tidak dapat melihat informasi materi kuliah maupun mengupload tugas yang diberikan dosen kepada mahasiswa. Sehingga pihak Universitas Bina Darma Membutuhkan sebuah aplikasi untuk mengingatkan mahasiswa Universitas Bina Darma untuk dapat melunasi siswa pembayaran angsuran mereka yang telah lewat tanggal tempo. Melalui pengiriman pesan ke aplikasi telegram yang telah dipasang bot telegram pada setiap akun telegram mahasiswa.

\section{METODOLOGI PENELITIAN}

\subsection{Metode Pengumpulan Data}

Dalam melakukan penelitian ini, metode pengumpulan data yang digunakan untuk mendapatkan data dan informasi ialah sebagai berikut:

1) Observasi, Melakukan pengamatan langsung terhadap objek yang diteliti untuk mengetahui bagaimana sistem yang sedang berjalan serta mampu membangun sistem lebih baik dari sebelumnya terhadap proses pembayaran uang semester dan pengingat batas pembayaran melalui Bot Telegram.

2) Wawancara, Wawancara dilakukan guna mengetahui data dan informasi yang tepat bersumber langsung dari Universitas Bina Darma agar perangkat lunak yang dibuat sesuai dengan yang dibutuhkan.

3) Studi Pustaka, Penulis juga mengumpulkan data, mencari dan mempelajari jurnal, buku, artikel, e-book dan situs- situs internet yang berhubungan dengan permasalahan objek yang diteliti untuk mendapatkan referensi yang jelas dan akurat untuk memperkuat atau memperjelas teori yang digunakan.

\subsection{Metode Penelitian}

Adapun metode penelitian yang digunakan dalam penelitian ini ialah mengunakan Metode penelitian deskriptif ialah peneliti dapat terjun langsung 
ketempat objek permasalah dan kebutuhan serta memudahkan peneliti mendapat informasi langsung dari sumbernya. dapat diartikan juga sebagai proses pemecahan masalah yang diteliti dengan mengamati keadaan suatu objek dalam penelitian dapat berupa orang, lembaga, masyarakat berdasarkan fakta-fakta atau apa adanya. Hal ini juga dikemukakan oleh Sugiyono (2005:21) bahwa Metode deskriptif adalah "suatu metode yang digunakan untuk menggambarkan atau menganalisis suatu hasil penelitian tetapi tidak digunakan untuk membuat kesimpulan yang lebih luas".

\subsection{Metode Pengembangan Perangkat lunak}

Proses Pengembangan Perangkat Lunak (Software Development Process) adalah suatu penerapan struktur pada pengembangan suatu Perangkat Lunak (Software), yang bertujuan untuk mengembangkan sistem dan memberikan panduan untuk menyukseskan proyek pengembangan sistem melalui tahapantahapan tertentu. Model Sekuensial Linier atau sering disebut Model Pengembangan Air Terjun, merupakan paradigma model pengembangan perangkat lunak paling tua, dan paling banyak dipakai. Model ini mengusulkan sebuah pendekatan perkembangan perangkat lunak yang sistematik dan sekunsial yang dimulai pada tingkat dan kemajuan sistem pada seluruh tahapan analisis, desain, kode, dan pengujian.

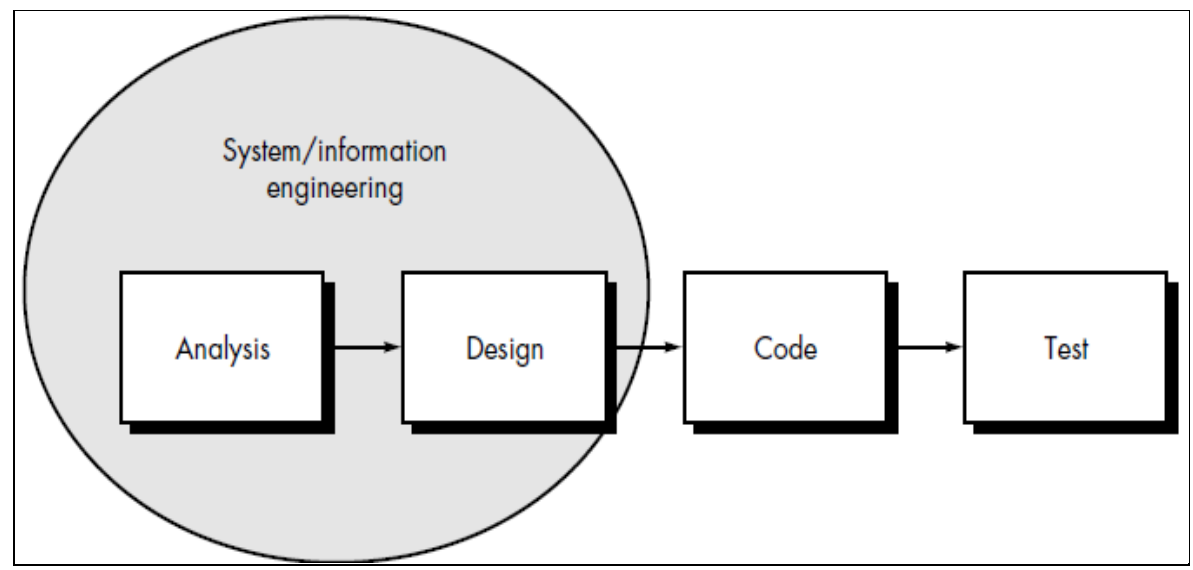

Gambar 1. Model Proses Waterfall Pressman (2001)

\subsection{Instant messaging}

Aplikasi instant messaging saat ini sangat populer di kalangan masyarakat. Tujuan utama aplikasi tersebut yaitu menyajikan fitur obrolan yang berjalan secara real time sehingga pesan langsung dapat terkirim dan diterima. Aplikasi 
instant messaging berjalan secara online atau dengan kata lain membutuhkan koneksi Internet. Saat ini terdapat banyak aplikasi instant messaging yang digunakan oleh masyarakat untuk mengobrol dengan individu maupun komunitas. Fitur yang disajikan aplikasi tersebut tidak hanya melalui text based saja, tetapi bisa juga untuk melakukan obrolan melalui suara, bertukar foto, audio, video hingga dokumen digital. Salah satu aplikasi yang memiliki fitur tersebut yaitu Telegram.

Telegram secara definisi menurut Telegram.org (Vico, 2014) merupakan alternatif layanan aplikasi perpesanan untuk ponsel (mobile) maupun dekstop yang berbasis cloud dengan tingkat keamanan tinggi serta kecepatan aksesnya. Aplikasi intant messaging tersebut tersedia untuk berbagai device seperti ponsel yang memiliki sistem operasi Android, iOS, Windows Phone, Ubuntu Touch. Tidak hanya dapat digunakan pada perangkat mobile, tetapi juga dapat berjalan pada sistem desktop seperti Windows, OS X, dan Linux. Meskipun aplikasi tersebut terlihat sederhana, tetapi gratis dan memiliki fitur yang lebih unggul dibandingkan dengan aplikasi instant messaging lainnya. Telegram diklaim sebagai aplikasi yang aman karena salah satunya memiliki fitur dimana menyediakan pilihan pesan end to end yang dienkripsi serta dapat hancur dengan sendirinya dalam jangka waktu tertentu.

\subsection{Telegram Bot}

Aplikasi instant messaging Telegram memiliki Application Progamming Interface $(A P I)$ yang dapat digunakan oleh publik. Berbeda dengan instant messaging lainnya seperti WhatsApp dan LINE. Pada instant messaging WhatsApp tidak menyediakan $A P$ I bagi publik, tetapi aplikasi LINE meyediakan $A P$ I dengan versi trial atau terbatas. API yang disediakan oleh Telegram dapat digunakan oleh siapapun dan tanpa batas. Telegram juga memiliki Bot API yang memungkinkan untuk dengan mudah membuat program yang menggunakan pesan Telegram sebagai antarmuka. API ini memungkinkan pengembang untuk menghubungkan Bot pada sistem Telegram. Telegram Bot merupakan cara khusus yang tidak memerlukan nomor telepon tambahan sebagai syarat khususnya. Akun Bot tersebut berfungsi sebagai antarmuka untuk kode yang dapat dijalankan pada server pengembang. Bot tersebut dapat melakukan beberapa pekerjaan yaitu:

1) Mengintegrasikan dengan layanan lainnya Bot dapat mengirimkan komentar jarak jauh atau mengendalikan smart home. Selain itu, Bot juga mampu mengirimkan pemberitahuan melalui Telegram ketika terjadi sesuatu di suatu tempat. 
2) Menciptakan alat khusus Bot mampu memberikan pemberitahuan maupun memberikan sebuah peringatan, ramalan cuaca, terjemahan, atau layanan lain.

3) Membangun single player ataupun multiplayer game keunggulan lainnya yaitu Bot mampu memainkan permainan seperti catur.

4) Membangun layanan sosial Sebuah Bot dapat menghubungkan orangorang untuk mencari mitra percakapan berdasarkan kepentingan bersama.

Dalam penggunaannya, pengembang tidak perlu repot untuk mengetahui protokol enkripsi Telegram karena hal tersebut akan ditangani oleh API Telegram. API Telegram berupa sebuah kode otentikasi yang disebut Token. Token tersebut didapatkan ketika telah melakukan pendaftaran akun pada Telegram. Pada implementasinya, pengembang hanya memerlukan token sebagai syarat untuk menggunakan Telegram Bot. Pada Telegram Bot API tersedia beberapa metode dalam pegiriman pesan yaitu get Me, send Message, send Document, send Photo, dan lain-lain ("All Method," n.d.). Setiap metode tersebut harus memiliki parameter chat_id yang mendefinisikan identitas target obrolan. Namun, terdapat perbedaan parameter pada setiap metode misalnya send Message wajib memiliki parameter text yang memiliki nilai berupa pesan yang akan dikirim. Sedangkan send Document harus memiliki parameter document yang berisi file yang akan dikirimkan. Penelitian ini memanfaatkan metode send Message untuk mengirimkan notifikasi singkat dan metode send Document untuk mengirimkan attachment file dalam format PDF.

\section{HASIL DAN PEMBAHASAN}

Setelah dilakukan penelitian di Universitas Bina Darma pada bagian LPPM, Universitas Bina Darma membutuhkan sebuah software yang dapat membantu mereka dalam mengingatkan mahasiswa yang sedang menunggak pembayaran SPP.

\subsection{Desain}

Desain perangkat lunak dilakukan untuk mengetahui rancangan antar muka seperti apa yang ingin dibuat sebelum pada proses pengodingan. Proses perancangan menggunakan Unified Modeling Language (UML) merupakan "suatu standar bahasa yang banyak digunakan dalam membuat analisis dan desain serta menggambarkan arsiterktur dalam pemograman berorientasi objek" (Rosa A.S dan M. Shalahuddin, 2016:137) yang terdiri dari 13 macam diagram namun pada tahap ini penulis mengunakan tiga diagram yaitu usecase diagram, Activity diagram dan class diagram. 


\section{1) Use case}

Use case digunakan untuk mengetahui fungsi apa saja yang ada di dalam sebuah sistem informasi dan siapa saja yang berhak menggunakan fungsi-fungsi itu. Berikut ini gambaran use case yang akan dibangun pada perangkat lunak:

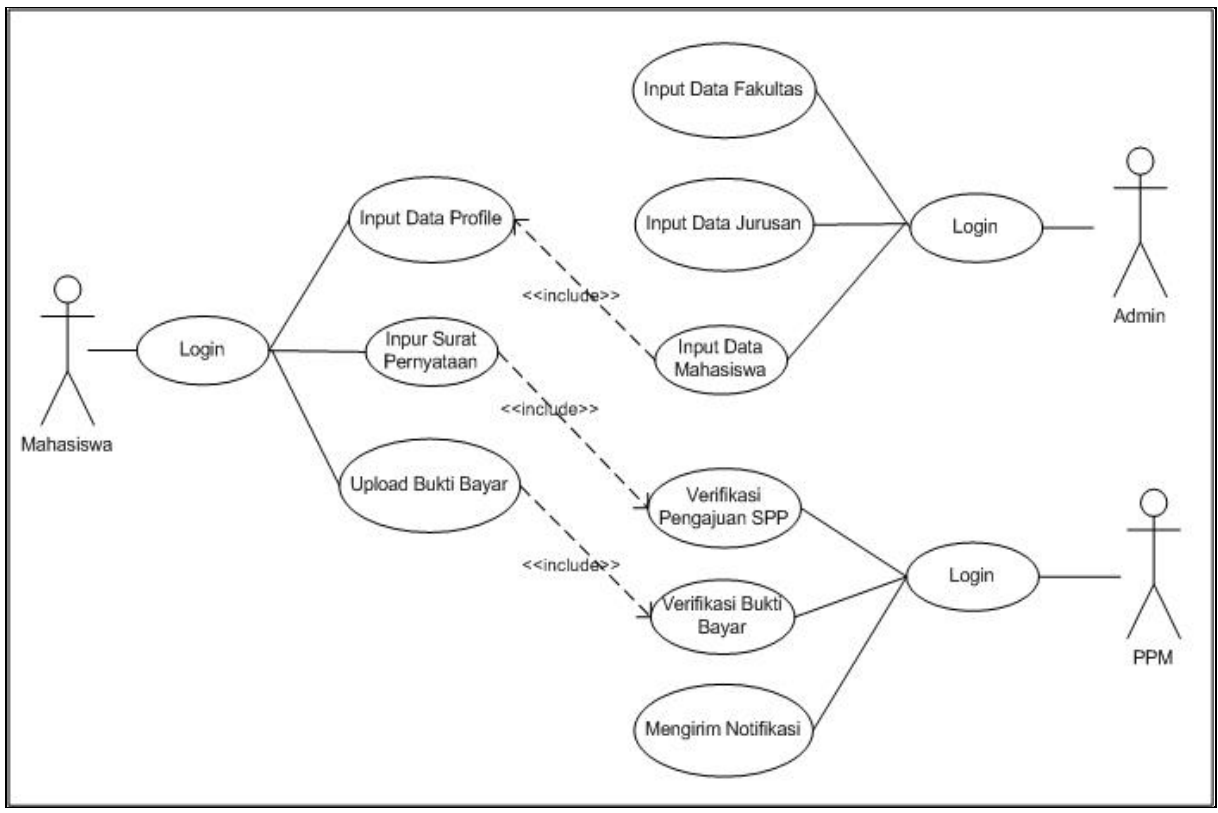

Gambar 2. Usecase

2) Activity Diagram

Activity Diagram digunakan untuk mendefinisikan rancangan proses bisnis dimana setiap urutan aktivitas yang digambarkan merupakan proses bisnis sistem yang didefinisikan, urutan atau pengelompokan tampilan dari interface dimana setiap aktivitas dianggap memiliki sebuah rancangan antarmuka tampilan, rancangan pengujian dimana setiap aktivitas dianggap memerlukan sebuah pengujian yang perlu didefinisikan kasus ujinya dan rancangan menu yang ditampilkan pada perangkat lunak. Berikut acitivity diagram yang terdapat pada perangkat lunak:

a. Activity Diagram Admin Fakultas, Dalam Activity admin fakultas yaitu menjelaskan tentang proses kegiatan yang dilakukan oleh Admin terhadap sistem yang akan digunakan yang terdiri dari adanya state dan transtation. 


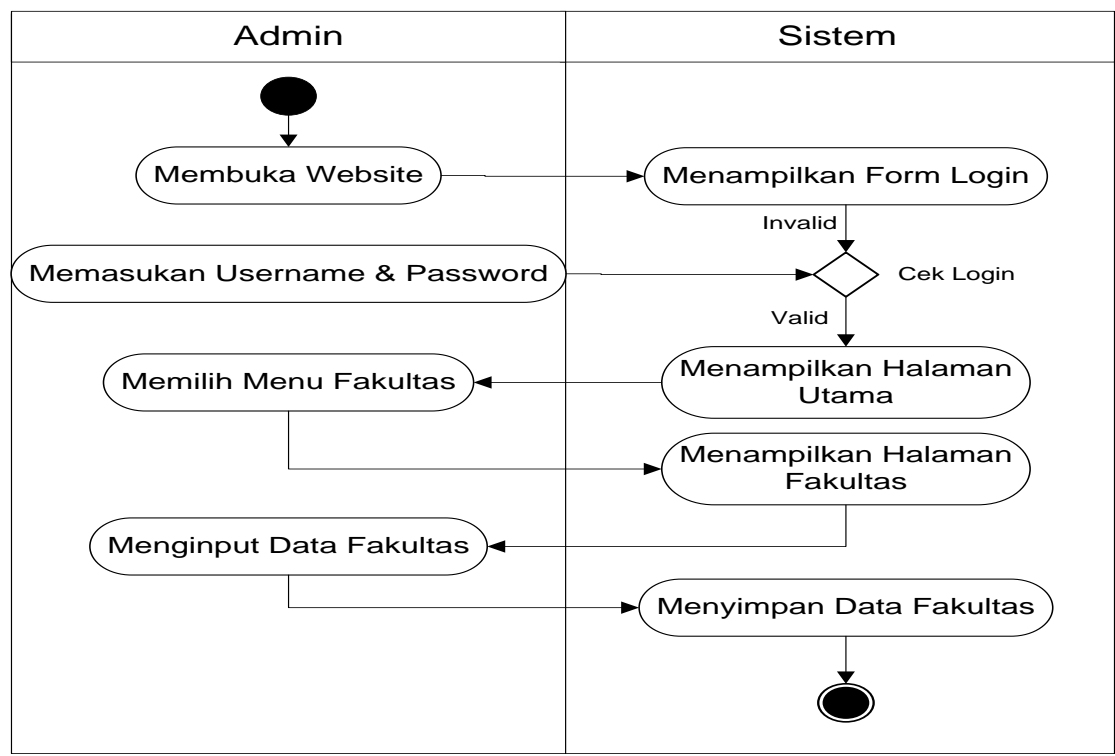

Gambar 3. Activity Diagram Fakultas

b. Activity Diagram Kirim Notifikasi, Dalam Activity kirim notifikasi yaitu menjelaskan tentang proses kegiatan yang dilakukan oleh Pusat Pelayanan Mahasiswa (PPM) terhadap sistem yang akan digunakan yang terdiri dari adanya state dan transtation.

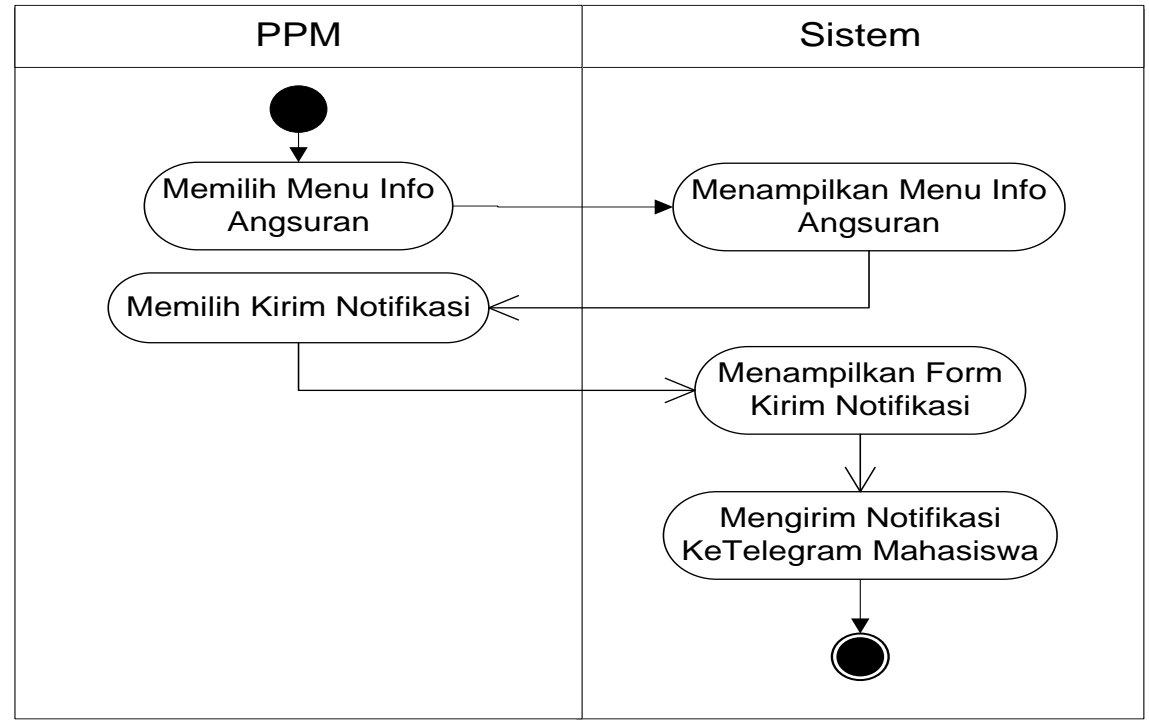

Gambar 4. Activity Diagram Kirim Notifikasi 


\section{3) Desain Interface}

Pada proses ini design interface dibuat atau dirancang untuk mengetahui bagaimana interaksi antara user dengan system. Penulis menggunakan justinmind sebagai tampilan interface yang memungkinkan masyarakat lebih terbayang dengan apa yang sebenarnya diinginkan sehingga dalam tahap evaluasi akan menjadi lebih mudah. Seperti gambar berikut ini :

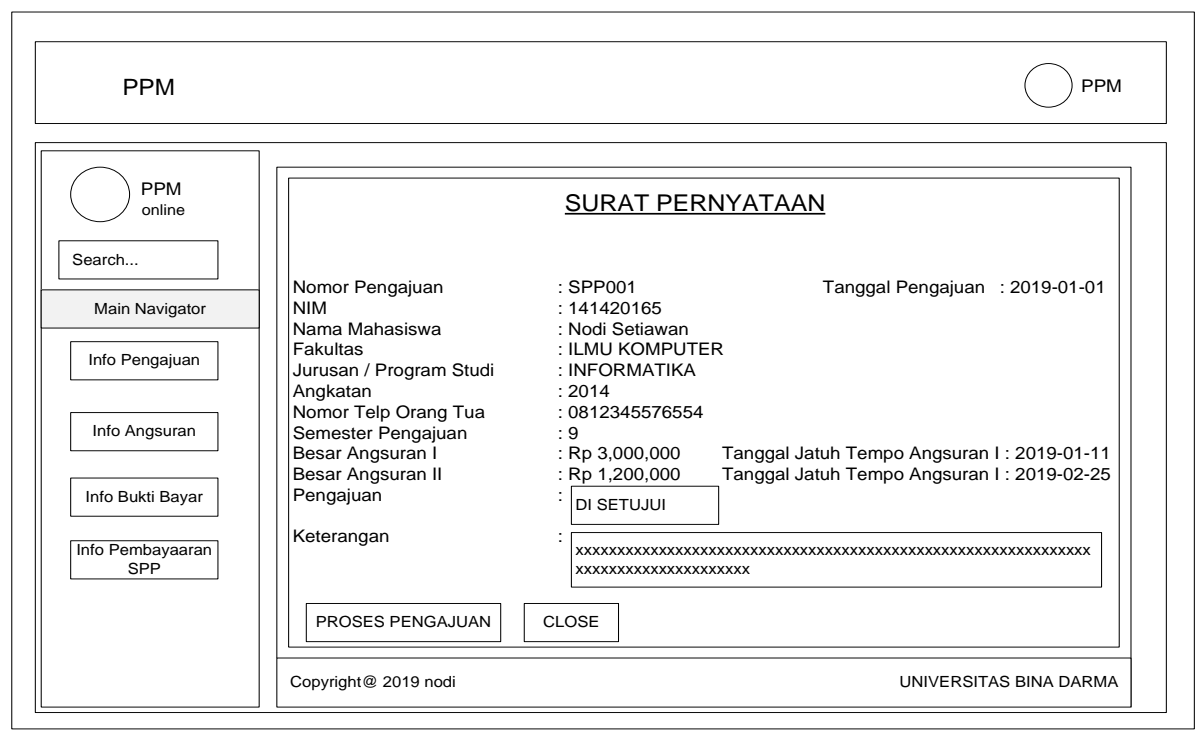

Gambar 5. Design Surat Pernyataan

\section{4) Pembuatan kode program}

Pada tahap ini, hasil dari perancangan pada tahap sebelumnya diterjemahkan ke dalam bahasa pemograman atau disebut juga langka pembuatan kode. Pada Pengembangan Perangkat Lunak Payment Remainder Di Universitas Bina Darma mengunakan bahasa pemograman PHP, MYSQL sebagai database serta Framework Bootstrap sebagai tampilan interface.

\section{5) Pengujian}

Setelah proses pembuatan perangkat lunak telah selesai, proses selanjutnya di uji mengunakan metode pengujian black box testing untuk mengetahui system yang telah dibuat sesuai dengan hasil rancangan sebelumnya dan meminimalisi kesalahan (error) dan memastikan keluaran yang dihasilkan sesuai dengan yang diinginkan. 


\subsection{Hasil}

Perangkat lunak payment remainder ini menggunakan PHP MySql untuk memproses dan telegram sebagain tempat untuk menerima pesan notifikasi. Dimana dari hasil pengujian menunjukan semua menu dan proses yang ada pada perangkat lunak payment semuanya dapat diterima yang ditunjukan dengan semua fungsi dapat berjalan dengan baik sesuai dengan fungsinya. Hasil dari penelitian ini dapat dilihat dari gambar berikut:

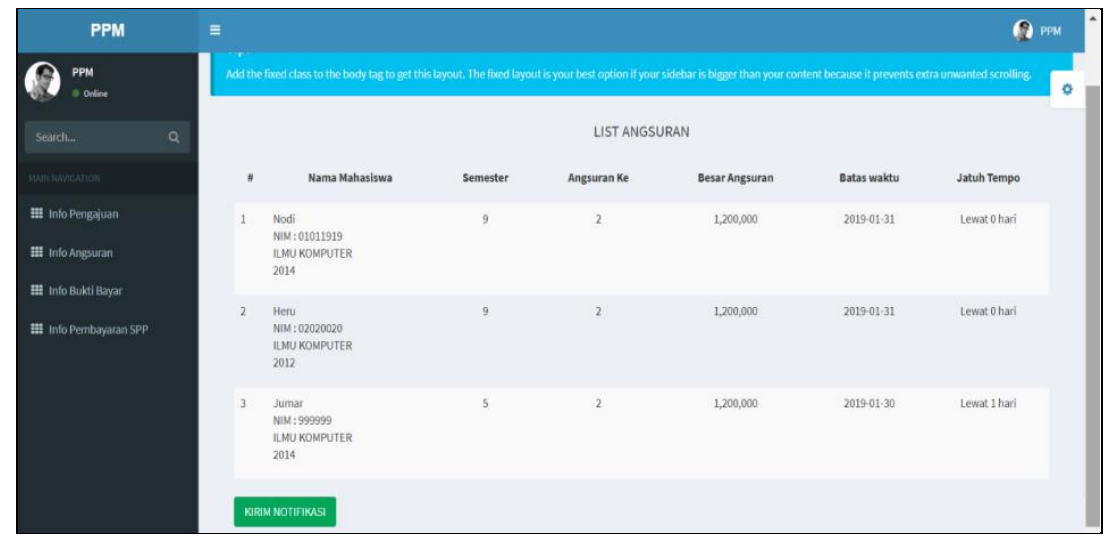

Gambar 6. Proses Pengiriman Pesan

Pihak Pusat Pelayanan Mahasiswa (PPM) dapat mengirim pesan notifikasi kepada mahasiswa yang sedang mengajukan pembayaran angsuran, notifikasi akan dikirim oleh Pusat Pelayanan Mahasiswa (PPM) jika akan masuk waktu jatuh tempo dan telah lewat jatuh tempo. Dapat dilihat pada gambar berikut:

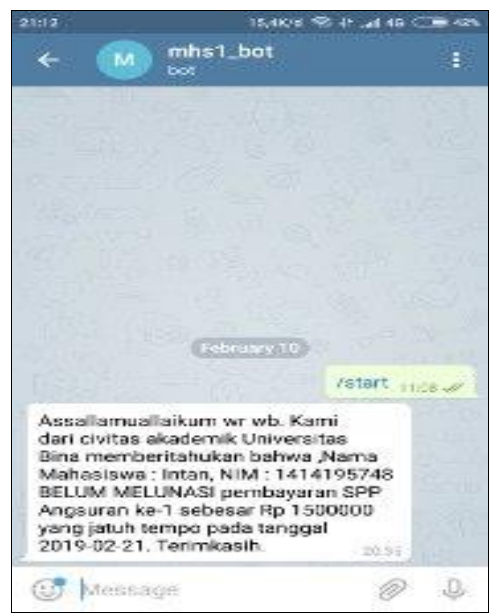

Gambar 7. Hasil Pengiriman Pesan Pada Telegram 


\section{KESIMPULAN}

Berdasarkan uraian yang telah dikemukakan pada bab-bab sebelumnya, maka dapat diambil beberapa kesimpulan dalam mencapai tujuan yang diinginkan. Adapun kesimpulan yang dapat diambil adalah sebagai berikut :

1) Penelitian ini menghasilkan perangkat lunak Payment Remainder di Universitas Bina Darma.

2) Perangkat lunak ini dapat membantu pihak Universitas Bina Darma dalam mengingatkan mahasiswa akan kewajiban mereka dalam melunasi sisa pembayaran spp.

3) Perangkat lunak ini dapat membantu Pusat Pelayanan Mahasiswa (PPM) mempermudah untuk mengingatkan mahasiswa akan kewajiban mereka.

4) Perangkat lunak ini dapat membantu mahasiswa dalam mengingatkan sisa pembayaran spp mereka, agar tidak terkena pemblokiran sisfo dan elearning Universitas Bina Darma.

\section{DAFTAR PUSTAKA}

Abdul, Kadir. 2003. Pengenalan Sistem Informasi. Andi : Yogyakarta. Definisi Metode Deskriptif https://idtesis.com/metode-deskriptif/ Diakses tanggal 21 Desember 2017.

Faisal, Andris. 2012. "Pengertian SMS Gateway". Tersedia dalam: (diakses tanggal 15 September 2017)

Muriarka, I Gede. "Perancangan SMS Gateway untuk Sistem Informasi Manajemen Keuangan STMIK STIKOM Bali".

Perdana, U.P. (2016). Pemanfaatan telegram bit api dalam layanan otentikasi tanpa password menggunakan algoritma time-based one-time password (TOTP). Kediri : Universitas Nusantara Persatuan Guru Republik Indonesia UN PGRI Kediri

Pressman, Roges S. 2010. Software engineering : a practitioner's approach. New York: Penerbit McGraw-Hill. Edisi ketujuh.

Prisky, Fradita Prayanatan. 2007. Pembuatan Sistem Basis Data Akademik Pada Aplikasi Sistem Informasi Akademik Melalui SMS dengan SQL Interbase 6.0 dan Pemograman Borlan Delphi.

Ramadhan, F. (2018). Pengembangan Media Pembelajaran Interaktif Matematika Dengan Botapi Media Sosial Telegram Di Akademi Farmasisurabaya. /T - EDU, 145-152.

Rosa A.S dan M.Shalahuddin. 2016. Rekayasa Perangkat Lunak Terstruktur dan Berorientasi Objek. Bandung: Penerbit Informaatika. Cetakan keempat.

Saputra, Agus. 2013. Membangun Aplikasi Toko Online dengan PHP dan SQL Server. Jakarta: PT Elex Media Komputindo.

Saribekyan, H., \& Margvelashvili. (2017).Security Analysis ofTelegram. Akaki. 
Sastrawangsa, G. (2017). Pemanfaatan Telegram Bot UntukAutomatisasi Layanan Dan Informasi Mahasiswa Dalam KonsepSmart Campus. Konferensi Nasional Sistem \& Informatika, 772-776.

Setiawan Alexander, Tedjokusuma Sukanto dan Suwanto Nathan. 2006. Perancangan dan Pembuatan Sistem Layanan SMS untuk Biro Administrasi Akademik Universitas Kristen Petra. Jurnal Informatika Vol. 7 No. 1

Sukamto, R. A., \& Salahuddin, M. (2014). Modul Pembelajaran Rekayasa Perangkat Lunak Terstuktur dan Berorientasi Objek. Bandung: Modula Bandung 